\title{
ОСОБЕННОСТИ СВОБОДНОРАДИКАЛЬНОГО ОКИСЛЕНИЯ В ТОЛСТОМ КИШЕЧНИКЕ ПРИ ЯЗВЕННОМ КОЛИТЕ И БОЛЕЗНИ КРОНА
}

М. В. Осиков ${ }^{1 凶}$, Е. В. Давыдова ${ }^{1}$, М. С. Бойко ${ }^{1}$, А. Е. Бакеева ${ }^{1}$, Н. В. Кайгородцева ${ }^{1}$, И. Р. Галеева ${ }^{1}$, А. А. Федосов², М. А. Ильиных Л. В. Воргова ${ }^{1}$

${ }^{1}$ Южно-Уральский государственный медицинский университет, Челябинск, Россия

2 Российский национальный исследовательский медицинский университет имени Н. И. Пирогова, Москва, Россия

Изучение особенностей накопления продуктов окислительной модификации белков (ОМБ) и липидов в кишечнике при болезни Крона (БК) и язвенном колите (ЯК) может иметь значение в патогенезе, диагностике и терапии этих заболеваний. Целью работы было изучить особенности свободнорадикального окисления (СРО) в толстом кишечнике, связь с клиническими симптомами при БК и ЯК. Для моделирования БК крысам Wistar вводили тринитробензосульфат, для ЯK — оксазолон. Клинический статус оценивали по Disease activity index (DAl). В толстом кишечнике определяли продукты пероксидного окисления липидов (ПОЛ) в гептановой и изопропанольной фазах, продукты ОМБ в спонтанном и металл-зависимом режимах. При БК и ЯК на 3-и и 7-е сутки увеличивается DAI (Mе $\left(Q_{25}-Q_{75}\right)$ : 7 (3-7) при БК на 3-и и 7-е сутки одинаково; 11 (11-11) и 11 (9-11) при ЯK на 3-и и 7-е сутки соответственно), в толстом кишечнике повышается количество первичных, вторичных и конечных продуктов ПОЛ в гептановой и изопропанольной фазах, суммарное количество продуктов ОМБ, при БК на 7-е сутки увеличивается доля вторичных продуктов ОМБ основного характера. Особенности СРО: при ЯК - накопление продуктов ПОЛ, при БК - продуктов ОМБ; при ЯК прежде всего накапливаются конечные продукты ПОЛ в гептановой фазе и вторичные продукты в изопропанольной; при БК - вторичные продукты ОМБ основного характера. При БК и ЯК установлена ассоциация DАІ с содержанием продуктов ПОЛ преимущественно в изопропанольной фазе, продуктов ОМБ в спонтанном режиме; наибольшее количество сильных связей зафиксировано при ЯК. По результатам исследования, роль изменений СРО в патогенезе БК и ЯК гораздо больше, что является предпосылкой для обозначения продуктов ПОЛ и ОМБ как диагностических маркеров, показателей эффективности терапии.

Ключевые слова: окислительный стресс, пероксидное окисление липидов, окислительная модификация белков, кишечник, язвенный колит, болезнь Крона Вклад авторов: М. В. Осиков - концепция и дизайн исследования, анализ полученных данных, написание и редактирование рукописи; Е. В. Давыдова концепция и дизайн исследования, анализ полученных данных, написание текста; М. С. Бойко, А. Е. Бакеева, Н. В. Кайгородцева, И. Р. Галеева сбор экспериментального материала, статистическая обработка и анализ полученных данных; А. А. Федосов - анализ результатов, написание и редактирование рукописи; М. А. Ильиных, Л. В. Воргова - анализ результатов, редактирование рукописи. Все авторы прочли и одобрили финальную версию статьи.

Соблюдение этических стандартов: исследование одобрено этическим комитетом ЮУГМУ г. Челябинск (протокол № 11 от 27 декабря 2017 г., протокол № 1 от 22 января 2020 г.). Эксперимент выполнен в стандартных условиях вивария ЮУГМУ при строгом соблюдении требований по уходу и содержанию животных, выводу их из эксперимента и утилизации в соответствии с Европейской конвенцией (ЕTS № 123 от 18.03.1986 г.

$\bowtie$ Для корреспонденции: Михаил Владимирович Осиков

ул. Воровского, д. 64, г. Челябинск, 454092; prof.osikov@yandex.ru

Статья получена: 18.04.2020 Статья принята к печати: 04.05.2020 Опубликована онлайн: 08.05.2020

DOI: $10.24075 /$ vrgmu.2020.027

\section{ASPECTS OF FREE RADICAL OXIDATION IN THE LARGE BOWEL IN ULCERATIVE COLITIS AND CROHN'S DISEASE}

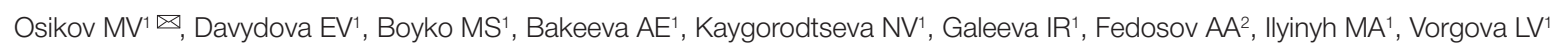

${ }^{1}$ South Ural State Medical University, Chelyabinsk, Russia

${ }^{2}$ Pirogov Russian National Research Medical University, Moscow, Russia

Research into the accumulation patterns of protein oxidative modification (POM) products and lipids in Crohn's disease (CD) and ulcerative colitis (UC) could have important implications for understanding the pathogenesis and improving the diagnosis and therapy for these diseases. The aim of this study was to investigate the aspects of free radical oxidation (FRO) in the large bowel and their possible correlations with clinical symptoms of UC and CD. In the Wistar rat model used in the experiment, CD was induced with 2,4,6-trinitrobenzenesulfonic acid, and UC was induced with oxazolone. Clinical status was assessed using the Disease activity index (DAl). Lipid peroxidation (LPO) products were measured in the heptane and isopropanol phases of the intestinal mucosa extract. POM products were measured following spontaneous and stimulated oxidation. The $\mathrm{DAl}\left(\mathrm{Me}\left(\mathrm{Q}_{25}-\mathrm{Q}_{75}\right)\right.$ ) was increased in both $\mathrm{CD}$ and $\mathrm{UC}$ on days 3 and 7 of the experiment: for $\mathrm{CD}$, it was equally increased on days 3 and $7(7$ (3-7)) and was 11 (11-11) and 11 (9-11) for UC on days 3 and 7 , respectively. The amount of primary, secondary and end LPO products in the heptane and isopropanol phases, as well as the total amount of POM products, was increased in the homogenized mucosa of the large bowel. In the CD group, the relative content of secondary basic POM products was increased on day 7 of the experiment. The following patterns of FRO were revealed: accumulation of LPO products in the UC group and accumulation of POM products in the CD group; UC is characterized by the accumulation of mostly LPO products in the heptane phase and secondary LPO products in the isopropanol phase; CD is characterized by the accumulation of secondary basic POM products. DAl scores were correlated with the amount of LPO products in the isopropanol phase and the amount of POM products in the spontaneous oxidation mode. The highest number of strong correlations was observed in the UC group. Our findings suggest a very serious contribution of FRO changes to the pathogenesis of $U C$ and $C D$, meaning that $\mathrm{LPO}$ and POM products could be regarded as diagnostic markers and indicators of treatment efficacy.

Keywords: oxidative stress, lipid peroxidation, protein oxidative modification, large bowel, ulcerative colitis, Crohn's disease

Author contribution: Osikov MV conceived and designed the study, analyzed the experimental data and contributed to writing the manuscript; Davydova EV conceived and designed the study, analyzed the experimental data and contributed to writing the manuscript; Boyko MS, Bakeeva AE, Kaygorodtseva NV, Galeeva IR collected the samples, performed statistical analysis and data interpretation; Fedosov AA analyzed the experimental data and contributed to writing the manuscript; llyinyh MA, Vorgova LV analyzed the experimental data and contributed to writing the manuscript. All authors read and approved the final version of the manuscript for publication.

Compliance with ethical standards: the study was approved by the Ethics Committee of South Ural State Medical University, Chelyabinsk (Protocol No. 11 dated December 27, 2017; Protocol № 1 dated January 22, 2020). The experiment was carried out under standard vivarium conditions in strict compliance with the guidelines on the care and use of animals for scientific purposes provided in the European Convention (ETS № 123 dated March 18, 1986, Strasbourg), European Commission Recommendation 2007/526/EC dated June 18, 2007, and Directive 2010/63/EU of the European Parliament and European Council dated September 22, 2010.

$\square$ Correspondence should be addressed: Mikhail V. Osikov

Vorovskogo, 64, Chelyabinsk, 454092; prof.osikov@yandex.ru

Received: 18.04.2020 Accepted: 04.05.2020 Published online: 08.05.2020

DOI: 10.24075/brsmu.2020.027 
В мире и, в частности, РФ число заболеваний органов пищеварения удваивается каждое десятилетие, что представляет собой глобальную медико-социальную проблему [1]. Несмотря на широкую вариабельность эпидемиологических данных рост заболеваемости язвенным колитом (ЯК) и болезнью Крона (БК), в том числе среди молодых социально активных и трудоспособных лиц, констатируют многие авторы $[2,3]$. Повсеместно регистрируется увеличение количества больных с ЯК и БК, заболеваемость составляет 3-62 и 50-70 случаев на 100 тыс. населения в год соответственно [4]. Только в США около 1,6 млн человек страдают от ЯК и БK $[5,6]$. Серьезную проблему при ЯК и БК составляет широкий спектр кишечных и внекишечных осложнений, увеличивающих финансовые затраты на госпитализацию, хирургическое и амбулаторное лечение.

Патогенез ЯК и БК до конца не ясен прежде всего в связи с широким спектром этиологических факторов, инициирующих активацию клеточных и гуморальных компонентов иммунной системы при участии Th1-, Th2зависимого иммунного ответа, изменения баланса $T h 17 / T_{\text {reg }}[7]$. При ЯК и БК наряду с цитокинами, ферментами, иммуноглобулинами и другими факторами в запуске и поддержании воспалительного процесса в стенке кишечника имеют значение активные формы кислорода (АФК) и азота, генерируемые активированными нейтрофилами, моноцитами/макрофагами, эндотелиоцитами, эпителиоцитами в условиях десицита факторов антиокислительной защиты [8-10]. АФК и активные формы азота, продукты их взаимодействия с белками и липидами могут выступать в роли маркеров повреждения тканей кишечника, отражающих тяжесть течения заболевания и эффективность проводимой терапии, а также служить мишенями при поиске новых персонифицированных терапевтических и профилактических подходов к регуляции локального редокс-статуса в толстом кишечнике при БК и ЯК [11-13]. В этом отношении представляет интерес изучение особенностей свободнорадикального окисления (СРО) и взаимосвязи показателей редокс-статуса в очаге повреждения кишечника и тяжести клинических проявлений при ЯК и БК.

Целью исследования было изучить особенности СРО в толстом кишечнике, его связь с клиническими проявлениями при ЯК и БК в эКсперименте in vivo.

\section{МАТЕРИАЛЫ И МЕТОДЫ}

Эксперимент проводили на 35 крысах-самцах линии Wistar массой 200-230 г. Животные были случайным образом разделены на три группы: группа $1(n=7)-$ интактный контроль; группа 2 ( $n=14)$ - животные с БК; группа 3 ( $n=14)$ - животные с ЯК. Для моделирования БК 30 мг тринитробензосульфоновой кислоты (ТНБС) (Sigmaaldrich; США) растворяли в 150 мл 50\%-го этанола, 0,2-0,3 мл в зависимости от массы тела полученного раствора вводили per rectum через полиуретановый катетер (ОАО «Синтез»; Россия) диаметром 2 мм на глубину 8 см [14]. ЯК моделировали двухэтапным введением оксазолона (Sigma-aldrich; США): на первом этапе проводили накожную сенсибилизацию нанесением на межлопаточную область 150 мкл 3\%-го спиртового раствора оксазолона, на втором этапе ректально на глубину 7-8 см вводили 150 мкл 3\%-го спиртового раствора оксазолона [15]. Для анестезии использовали препарат «Золетил-100» (МНН: тилетамина гидрохлорид) (Virbac Sante Animale; Франция) в дозе 20 мг/кг. БК и ЯК верифицировали по клинической картине и морфологии очага повреждения в кишечнике. Исследования проводили на 3-и и 7-е сутки. Клинический статус оценивали ежедневно в баллах по модифицированной шкале Disease activity index (DAl), адаптированной для крыс [16, 17]. Показатели параметров представлены в (табл. 1). Под параметром «жидкий стул» понимали несформированные каловые массы с консистенцией пасты или жидкие. Под термином «диарея» понимали отсутствие оформленного стула с частотой дефекаций более трех раз в сутки. Ректальное кровотечение определяли как присутствие свежей крови на шерсти вокруг ануса и в каловых массах. Наличие скрытой крови в каловых массах определяли с помощью бензидиновой реакции.

Для приготовления 10\%-го гомогената слизистой оболочки толстого кишечника проксимальную часть ободочной кишки извлекали из брюшной полости, помещали в охлажденный 0,1 М раствор фосфатного буфера $(\mathrm{pH} 7,4)$, после чего около 100 мг ткани гомогенизировали в стеклянном механическом гомогенизаторе в соотношении 1: 10 в течение 3 мин при температуре не выше $4{ }^{\circ} \mathrm{C}$ с последующим получением 1 мл гомогената. Содержание продуктов пероксидного окисления

Таблица 1. Параметры для определения индекса активности болезни (DAl)

\begin{tabular}{|c|c|c|}
\hline Параметр & Балл & Описание \\
\hline \multirow{5}{*}{ Потеря массы тела } & 0 & Нет потери \\
\hline & 1 & $1-5 \%$ \\
\hline & 2 & $6-10 \%$ \\
\hline & 3 & $11-20 \%$ \\
\hline & 4 & Более $20 \%$ \\
\hline \multirow{3}{*}{ Консистенция стула } & 0 & Нормальный стул \\
\hline & 2 & Неоформленный стул \\
\hline & 4 & Диарея \\
\hline \multirow{4}{*}{ Ректальное кровотечение } & 0 & Нет крови в фекалиях \\
\hline & 1 & Позитивная бензидиновая проба в фекалиях \\
\hline & 2 & Позитивная бензидиновая проба в фекалиях и визуальное определение крови в фекалиях \\
\hline & 4 & Ректальное кровотечение, кровь вокруг ануса \\
\hline
\end{tabular}


липидов (ПОЛ) в гомогенате определяли экстракционноспектрофотометрическим методом на спектрофотометре «СФ-56» («ЛОМО-Спектр»; Санкт-Петербург) по методике Волчегорского И. А. и соавт. [18, 19]. В гептановой и изопропанольной фазах липидного экстракта измеряли оптическую плотность при 220 нм (содержание изолированных двойных связей), 232 нм (содержание диеновых конъюгатов - ДК), 278 нм (содержание кетодиенов и сопряженных триенов - КД и СТ), 400 нм (основания Шиффа - ШО). Относительное содержание продуктов ПОЛ выражали в единицах индексов окисления (е.и.о.): E232/E220 (ДК), Е278/E220 (КД и СТ) и E400/E220 (ШО). Продукты окислительной модификации белков (ОМБ) в гомогенате определяли по реакции карбонильных производных белков с 2,4-динитрофенилгидразином в спонтанном и металл-зависимом по реакции Фентона режимах с последующей регистрацией на спектрофотометре альдегиддинитрофенилгидразонов (АДНФГ) и кетондинитрофенилгидразонов (КДНФГ) в ультрафиолетовой части спектра и области видимого света $[20,21]$. Результат выражали в единицах оптической плотности на 1 мг белка (у.е./мг) или в относительных величинах (\%). Резервно-адаптационный потенциал (РАП, \%) рассчитывали путем отношения продуктов спонтанного окисления к индуцированному. Результаты обрабатывали с помощью программы IBM SPSS Statistics 19 («SPSS: An IBM Company»; США). Показатели представлены в виде медианы $(\mathrm{Me})$ и квартилей $\left[\mathrm{Q}_{1}-\mathrm{Q}_{3}\right]$. Значимость различий между группами оценивали при помощи критериев Краскелла-Уоллиса, Манна-Уитни, Вальда-Вольфовитца. Для выявления связи между изучаемыми параметрами использовали коэффициент корреляции Спирмена $(R)$. Отличия считали статистически значимыми при $p<0,05$.

\section{РЕЗУЛЬТАТЫ ИССЛЕДОВАНИЯ}

При экспериментальной БК, начиная с 3-х суток наблюдения, у животных были зафиксированы увеличение частоты десекации, изменение консистенции кала, кровь в каловых массах; на 7-е сутки наблюдения к указанным признакам добавились снижение массы тела и увеличение выраженности симптомов, что нашло отражение в статистически значимом увеличении индекса DAl на 3-и и 7-е сутки эксперимента (табл. 2). Кроме того, было отмечено снижение двигательной активности животных. В динамике БK значение DAI на 7-е сутки статистически значимо превышало значения на 3-и сутки $(p<0,05)$. В липидном экстракте слизистой оболочки толстого кишечника при БК изменяется содержание продуктов ПОЛ (табл. 3). Так, на 3-и сутки увеличивается в гептановой фазе количество первичных и вторичных продуктов, в изопропанольной фазе - первичных, вторичных и конечных продуктов ПОЛ. На 7-е сутки в гептановой и изопропанольной фазах липидного экстракта увеличивается содержание первичных, вторичных и конечных продуктов ПОЛ. В динамике БК в изопропанольной фазе содержание первичных и конечных продуктов ПОЛ нарастает от 3-х к 7-м суткам $(p<0,01)$. Далее при экспериментальной БК нами была проведена оценка содержания продуктов ОМБ в спонтанном и индуцированном режимах в гомогенате толстого кишечника (табл. 3).

Обнаружено, что на 3-и и 7-е сутки эксперимента увеличивается суммарное количество карбонильных производных белков - необратимых продуктов окислительного стресса, формирующихся за счет окисления нескольких аминокислотных остатков, а также взаимодействия продуктов пероксидного окисления липидов и редуцирующих сахаров. В динамике БК суммарное содержание продуктов ОМБ возрастает на 7-е сутки по сравнению с 3-ми сутками наблюдения ( $p<0,01)$. Анализ относительного содержания компонентов ОМБ выявил, что на 7-е сутки БК снижается доля первичных продуктов - альдегидов и увеличивается доля вторичных продуктов - кетонов. Поскольку в области УФ-спектра накапливаются карбонильные производные нейтрального характера, а в видимой - основного характера, относительный анализ суммарного содержания карбонилов в области УФ-света и в области видимого света позволяет оценить природу образовавшихся продуктов в динамике БК. Так, на 3-и сутки БК относительное содержание продуктов ОМБ основного и нейтрального характера не отличается от группы интактных животных. На 7-е сутки эксперимента засиксировано смещение спектра в сторону образования продуктов ОМБ основного характера, о чем свидетельствуют снижение суммарного относительного содержания продуктов в области УФ-спектра и повышение суммарного относительного содержания продуктов в области видимого света. Проведена оценка резервноадаптационного потенциала в гомогенате толстого кишечника при экспериментальной БК путем подсчета отношения общего содержания продуктов ОМБ в спонтанном режиме и металл-индуцированном. Для этого исследовано содержание продуктов ОМБ в гомогенате толстого кишечника после индукции окисления белков компонентами реакционной смеси, включающей $\mathrm{Fe}^{2+}$ и $\mathrm{H}_{2} \mathrm{O}_{2}$, что сопровождается образованием высокореактогенного радикала ОН - в реакции Фентона. Обнаружено, что суммарное содержание продуктов ОМБ в металл-индуцированном режиме в гомогенате толстого кишечника повышается на 3-и и 7-е сутки экспериментальной БК, на 3-и сутки относительное содержание первичных и вторичных продуктов ОМБ основного и нейтрального характера не отличается от группы интактных животных, на 7-е сутки снижается доля альдегидов нейтрального характера и увеличивается доля кетонов основного. Как видно, изменения показателей ОМБ в металл-индуцированном режиме по своей направленности соответствуют изменениям показателей ОМБ в спонтанном режиме. Общий резервно-адаптационный потенциал значительно повысился на 3 сутки экспериментальной БК, к 7-м суткам наблюдения - статистически значимо не отличался от группы интактных животных. Данное изменение резервно-адаптационного потенциала обусловлено на 3-и сутки повышением резервно-адаптационного потенциала АДНФГ и КДНФГ в области УФ-спектра и видимого спектра, но преимущественно - КДНФГ, регистрируемых в области видимого спектра.

Таблица 2. Индекс активности болезни у крыс при ЯК и БK (Me $\left(\mathrm{Q}_{25}-\mathrm{Q}_{75}\right)$ )

\begin{tabular}{|c|c|c|c|c|c|}
\hline \multirow{2}{*}{ Показатель } & $\begin{array}{c}\text { Группа 1 } \\
\text { Интактные } \\
(n=7)\end{array}$ & \multicolumn{2}{|c|}{ 3-и сутки эксперимента } & \multicolumn{2}{|c|}{ 7-е сутки эксперимента } \\
\cline { 3 - 6 } & 0 & $\begin{array}{c}\text { Группа 2 } \\
\text { БK }(n=7)\end{array}$ & $\begin{array}{c}\text { Группа 3 } \\
\text { ЯК }(n=7)\end{array}$ & $\begin{array}{c}\text { Группа 2 } \\
\text { БК }(n=7)\end{array}$ & $\begin{array}{c}\text { Группа 3 } \\
\text { 9K }(n=7)\end{array}$ \\
\hline DAl, y.e. & $7(3,00-7,00)^{*}$ & $7(3,00-7,00)^{*}$ & $11(11,00-11,00)^{*}$ & $11(9,00-11,00)^{*}$ \\
\hline
\end{tabular}


При экспериментальном ЯК у животных на 3-и сутки наблюдения снижается масса тела, увеличивается число дефекаций, консистенция кала становится жидкой, появляется кровь, определяемая как визуально, так и с проведением бензидиновой пробы, на 7-е сутки выраженность клинических признаков возрастает, что отражается в статистически значимом увеличении индекса DAI (см. табл. 2). В динамике ЯK значение DAI на 7-е сутки статистически значимо превышает значения на 3-и сутки $(p<0,05)$. При оценке продуктов ПОЛ в гомогенате слизистой оболочки толстого кишечника при ЯК на З-и сутки зарегистрировано статистически значимое увеличение в гептановой и изопропанольной фазах липидного экстракта уровня первичных, вторичных и конечных продуктов (табл. 3). На 7-е сутки ЯК обнаружены аналогичные изменения: статистически значимое увеличение в гептановой и в изопропальной фазах первичных, вторичных и конечных продуктов ПОЛ. В динамике экспериментального ЯК содержание в изопропанольной фазе первичных, вторичных продуктов ПОЛ снижается от 3-х к 7-м суткам $(p<0,01)$.

При экспериментальном ЯК в слизистой оболочке толстой кишки отмечено статистически значимое увеличение суммарного содержания ОМБ в спонтанном режиме на 3-и и 7-е сутки (см. табл. 3). При этом относительное количество АДНФГ снижается, а КДНФГ увеличивается на 3-и и 7-е сутки наблюдения, относительное количество карбонильных производных основного характера увеличивается, а нейтрального - снижается на 7-е сутки эксперимента, о чем свидетельствуют повышение суммарного относительного содержания продуктов ОМБ в области видимого света, снижение - в УФ-области. Анализ

Таблица 3. Содержание маркеров СРО в гомогенате слизистой оболочки толстого кишечника у крыс при ЯK и БK (Ме $\left.\left(Q_{25}-Q_{75}\right)\right)$

\begin{tabular}{|c|c|c|c|c|c|}
\hline \multirow{3}{*}{ Показатели } & \multirow{2}{*}{$\frac{\text { Группа } 1}{\text { Интактные }}$} & \multicolumn{2}{|c|}{ 3-и сутки эксперимента } & \multicolumn{2}{|c|}{ 7-е сутки эксперимента } \\
\hline & & Группа 2 & Группа 3 & Группа 2 & Группа 3 \\
\hline & $(n=7)$ & $\mathrm{EK}(n=7)$ & ЯK $(n=7)$ & $\mathrm{EK}(n=7)$ & ЯK $(n=7)$ \\
\hline \multirow{2}{*}{ ДК (г), е.и.о. } & 0,63 & 0,79 & 0,79 & 0,75 & 0,76 \\
\hline & $(0,55-0,65)$ & $(0,79-0,81)^{\star}$ & $(0,75-0,81)^{\star}$ & $(0,74-0,81)^{\star}$ & $(0,75-0,77)^{\star}$ \\
\hline \multirow{2}{*}{$\begin{array}{l}\text { КДист (г), } \\
\text { е.и.о. }\end{array}$} & 0,06 & 0,09 & 0,08 & 0,07 & 0,09 \\
\hline & $(0,05-0,06)$ & $(0,06-0,09)^{\star}$ & $(0,07-0,08)^{*}$ & $(0,06-0,09)$ & $(0,09-0,11)^{\star} \#$ \\
\hline \multirow{2}{*}{$\begin{array}{l}\text { Шо (г), } \\
\text { e.и.o. }\end{array}$} & 0,01 & 0,01 & 0,03 & 0,03 & 0,05 \\
\hline & $(0,01-0,02)$ & $(0,01-0,01)$ & $(0,02-0,04)^{*} \#$ & $(0,03-0,04)^{*}$ & $(0,04-0,06)^{*} \#$ \\
\hline \multirow{2}{*}{$\begin{array}{l}\text { ДК (n), } \\
\text { e.u.o. }\end{array}$} & 0,34 & 0,38 & 0,38 & 0,43 & 0,43 \\
\hline & $(0,32-0,36)$ & $(0,38-0,45)^{\star}$ & $(0,33-0,43)^{\star}$ & $(0,41-0,45)^{\star}$ & $(0,43-0,45)^{\star}$ \\
\hline \multirow{2}{*}{$\begin{array}{l}\text { КДист (и), } \\
\text { е.и.о. }\end{array}$} & 0,31 & 0,61 & 0,72 & 0,51 & 0,58 \\
\hline & $(0,29-0,32)$ & $(0,61-0,71)^{\star}$ & $(0,56-0,91)^{\star} \#$ & $(0,51-0,55)^{\star}$ & $(0,57-0,59)^{*} \#$ \\
\hline \multirow{2}{*}{$\begin{array}{l}\text { шо (n), } \\
\text { e.и.o. }\end{array}$} & 0,01 & 0,08 & 0,07 & 0,14 & 0,11 \\
\hline & $(0,01-0,02)$ & $(0,08-0,11)^{\star}$ & $(0,07-0,09)^{*}$ & $(0,12-0,14)^{*}$ & $(0,11-0,14)^{*}$ \\
\hline \multirow{2}{*}{$\begin{array}{c}\text { S ОМБ спонт., } \\
\text { у.е./мг }\end{array}$} & 141,86 & 324,21 & 194,91 & 392,31 & 343,48 \\
\hline & $(136,04-166,74)$ & $(313,48-340,93)^{*}$ & $(182,07-201,07)^{\star} \#$ & $(272,17-497,71)^{\star}$ & $(332,13-358,22)^{*} \#$ \\
\hline \multirow{2}{*}{$\begin{array}{l}\text { АДНФГ, } \\
\text { СПОНт. }\end{array}$} & 93,71 & 92,59 & 91,79 & 89,13 & 90,71 \\
\hline & $(93,69-93,71)$ & $(91,61-93,41)$ & $(91,48-91,98)^{\star}$ & $(88,99-90,02)^{\star}$ & $(90,69-90,71)^{\star}$ \\
\hline \multirow{2}{*}{$\begin{array}{l}\text { КДНФГГ, \% } \\
\text { спонт., \% }\end{array}$} & 6,29 & 7,41 & 8,51 & 11,02 & 10,58 \\
\hline & $(6,09-6,31)$ & $(6,59-8,38)$ & $(8,21-9,44)^{*} \#$ & $(10,93-11,12)^{*}$ & $(10,31-11,34)^{*}$ \\
\hline \multirow{2}{*}{$\begin{array}{c}\text { uv, } \\
\text { спонт., \% }\end{array}$} & 96,57 & 95,57 & 95,32 & 92,88 & 94,58 \\
\hline & $(96,41-96,58)$ & $(95,27-96,01)$ & $(95,29-95,74)$ & $(92,72-93,59)^{*}$ & $(94,23-95,21)^{*} \#$ \\
\hline \multirow{2}{*}{$\begin{array}{c}\text { vs, } \\
\text { спонт., \% }\end{array}$} & 3,42 & 4,42 & 4,71 & 7,11 & 5,76 \\
\hline & $(3,41-3,59)$ & $(3,99-4,72)$ & $(4,67-5,85)$ & $(6,41-7,27)^{\star}$ & $(5,41-6,77)^{\star} \#$ \\
\hline \multirow{2}{*}{$\begin{array}{c}\text { S ОМБ индуц., } \\
\text { у.е./мг }\end{array}$} & 266,76 & 380,93 & 321,71 & 662,05 & 544,66 \\
\hline & $(256,21-280,81)$ & $(373,56-427,51)^{*}$ & $(284,89-377,77)^{*} \#$ & $(643,29-690,09)^{\star}$ & $(479,92-600,42)^{*} \#$ \\
\hline \multirow{2}{*}{$\begin{array}{c}\text { АДНФГ } \\
\text { индуц., \% }\end{array}$} & 86,94 & 89,34 & 83,13 & 81,15 & 83,07 \\
\hline & $(85,98-88,02)$ & $(89,03-90,07)$ & $(82,89-85,89)^{*} \#$ & $(81,01-83,48)^{\star}$ & $(82,62-87,41)^{\star}$ \\
\hline \multirow{2}{*}{$\begin{array}{c}\text { КДНФГ, } \\
\text { индуц., \% }\end{array}$} & 13,05 & 10,65 & 16,86 & 18,84 & 16,92 \\
\hline & $(11,97-14,01)$ & $(9,92-10,96)$ & $(14,11-17,11)^{*} \#$ & $(16,51-18,99)^{*}$ & $(12,58-17,37)^{\star}$ \\
\hline \multirow{2}{*}{$\begin{array}{c}\text { uv, } \\
\text { индуц., \% }\end{array}$} & 88,99 & 91,91 & 85,67 & 84,52 & 86,13 \\
\hline & $(88,99-90,83)$ & $(91,27-92,31)$ & $(85,44-85,44)^{*} \#$ & $(83,91-86,37)^{\star}$ & $(85,01-89,91)$ \\
\hline \multirow{2}{*}{$\begin{array}{c}\text { vs, } \\
\text { индуц., \% }\end{array}$} & 11,01 & 8,09 & 14,32 & 15,47 & 13,89 \\
\hline & $(9,16-11,01)$ & $(7,69-8,72)$ & $(12,19-14,55)^{\star} \#$ & $(13,62-16,08)^{*}$ & $(10,09-14,98)$ \\
\hline \multirow{2}{*}{ РАП, \% } & 54,71 & 80,25 & 49,51 & 57,15 & 42,31 \\
\hline & $(51,53-56,71)$ & $(74,89-87,87)^{*}$ & $(46,77-51,14)^{*} \#$ & $(50,11-59,71)$ & $(28,17-47,78)^{\star} \#$ \\
\hline
\end{tabular}

Примечание: * - значимые $(p<0,01)$ различия с группой 1, \# - с группой 2. Показатели отражают содержание продуктов ПОЛ в гептановой (г) и изопропанольной (и) фазах липидного экстракта гомогената слизистой оболочки толстого кишечника. 
Таблица 4. Корреляция между индексом активности болезни (DAI, у.е.) и показателями CРО у крыс при ЯК и БК

\begin{tabular}{|c|c|c|c|c|}
\hline \multirow{3}{*}{ Показатели } & \multicolumn{2}{|c|}{ 3-и сутки эксперимента } & \multicolumn{2}{|c|}{ 7-е сутки эксперимента } \\
\hline & Группа 2 & Группа 3 & Группа 2 & Группа 3 \\
\hline & $\mathrm{EK}(n=7)$ & ЯK $(n=7)$ & $\mathrm{EK}(n=7)$ & ЯK $(n=7)$ \\
\hline ДК (г), е.и.о. & $R=0,15$ & $R=0,58$ & $R=0,43$ & $R=0,72$ \\
\hline КДиСТ (г), е.и.о. & $R=0,51$ & $R=0,82$ & $R=0,32$ & $R=0,66$ \\
\hline ШО (г), е.и.о. & $R=0,13$ & $R=0,17$ & $R=0,43$ & $R=0,88$ \\
\hline ДК (и), е.и.о. & $R=0,27$ & $R=0,75$ & $R=0,51$ & $R=0,92$ \\
\hline КДиСТ (и), е.и.о. & $R=0,64$ & $R=0,76$ & $R=0,51$ & $R=0,88$ \\
\hline ШО (и), е.и.о. & $R=0,32$ & $R=0,31$ & $R=0,67$ & $R=0,72$ \\
\hline S ОМБ спонт., у.е./мг & $R=0,69$ & $R=0,77$ & $R=0,83$ & $R=0,89$ \\
\hline S ОМБ инд., у.е./Мг & $R=0,41$ & $R=0,85$ & $R=0,63$ & $R=0,81$ \\
\hline
\end{tabular}

Примечание: полужирным шрифтом выделены значимые $(p<0,05)$ связи.

содержания при экспериментальном ЯК продуктов ОМБ в металл-индуцированном режиме показал повышение на 3-и и 7-е сутки суммарного количества продуктов ОМБ. Относительное количество АДНФГ снижается, а относительное количество КДНФГ увеличивается на 3-и и 7-е сутки эксперимента. Выявлено преимущественное повышение суммарного относительного содержания продуктов ОМБ в области видимого света на 3-и сутки наблюдения, что указывает на смещение спектра продуктов ОМБ в сторону образования АДНФГ и КДНФГ основного характера. Общий резервно-адаптационный потенциал статистически значимо снижался на 3-и и 7-е сутки экспериментального ЯК.

При проведении корреляционного анализа установлены ассоциации между интегральным показателем клинического статуса DAI и содержанием продуктов ПОЛ и продуктов ОМБ в гомогенате слизистой оболочки толстого кишечника (табл. 4). На 3-и сутки эксперимента ассоциации представлены при БК средней силы связями DAI с содержанием вторичных продуктов ПОЛ в гептановой и изопропанольной фазах, суммарным количеством продуктов ОМБ в спонтанном режиме, при ЯК - сильными связями DAI с содержанием вторичных продуктов ПОЛ в гептановой фазе, первичных и вторичных продуктов в изопропанольной фазе, суммарным количеством продуктов ОМБ в спонтанном и индуцированном режимах. На 7-е сутки эксперимента ассоциации представлены при БK связями DAI с содержанием первичных продуктов ПОЛ в гептановой фазе, первичных, вторичных и конечных продуктов ПОЛ в изопропанольной фазе, суммарным количеством продуктов ОМБ в спонтанном и индуцированном режимах, при ЯK - сильными связями DAI с содержанием первичных и конечных продуктов ПОЛ в гептановой фазе, первичных, вторичных и конечных продуктов в изопропанольной фазе, суммарным количеством продуктов ОМБ в спонтанном и индуцированном режимах. Наибольшее количество сильных связей было выявлено при ЯК: из 12 связей 10 сильных, в то время как при БК из 9 связей обнаружена только одна сильная.

\section{ОБСУЖДЕНИЕ РЕЗУЛЬТАТОВ}

При экспериментальном моделировании БК и ЯК наблюдаемая клиническая картина характерна для этих заболеваний, что позволяет применять представленные модели с использованием ТНБС и оксазолона для изучения патогенеза изменений гомеостаза. Потеря веса у крыс в среднем не превышала 10\%, принято считать, что она обусловлена как диареей, так и системным воспалительным ответом, в частности анорексигенным эффектом некоторых провоспалительных цитокинов [22]. Полагают, что ТНБС выступает в роли гаптена и индуцирует после ректального введения Th1-зависимый иммунный ответ с участием различных провоспалительных цитокинов и медиаторов против гаптен-модифицированных аутологичных белков (антигенов) в стенке толстого кишечника или белков кишечной микробиоты, что приводит к трансмуральной инфильтрации лейкоцитами и воспалению [23-25]. Оксазолон рассматривают в качестве гаптена, опосредующего Th2-зависимый иммунный ответ, характерный для ЯК, и большинство исследователей предпочитают его как наиболее востребованный агент при моделировании этого заболевания у крыс [26]. Используемый в качестве растворителя для ТНБС и оксазолона 50\%-й раствор этилового спирта вызывает дополнительное повреждение слизистой оболочки толстого кишечника [27].

При экспериментальных БК и ЯК наряду со снижением массы тела, увеличением частоты и изменением консистенции стула, а также наличием крови в каловых массах, зафиксировано накопление продуктов ПОЛ в слизистой оболочке толстого кишечника. Такое накопление выявлено как в изопропанольной фазе липидного экстракта слизистой толстого кишечника, которая аккумулирует преимущественно фосфолипиды клеточных мембран, так и в гептановой фазе (в триацилглицеридах). Кроме того, обнаружено накопление продуктов ОМБ, преимущественно вторичных - КДНФГ и преимущественно основного характера в спонтанном и индуцированном режимах. Это позволяет говорить об аккумуляции поздних маркеров окислительной деструкции белка и преимущественно фррагментации белков под влиянием совместного действия радикалов $\mathrm{OH}^{*}$ и О О ${ }^{\prime}[20,28,29]$. Белковые фрагменты высокоустойчивы к протеолизу, имеют токсичные свойства и могут инициировать апоптоз или некроз клеток, расширяя зону вторичной альтерации [30]. Есть ряд особенностей СРО в толстом кишечнике при БК и ЯК в отношении окислительной деструкции липидов и белков. Во-первых, сравнительный анализ показывает, что на 3-и сутки эксперимента содержание конечных продуктов ПОЛ в гептановой фракции и вторичных продуктов ПОЛ в изопропанольной фракции липидного экстракта толстого 
кишечника, а также на 7-е сутки количество вторичных и конечных продуктов ПОЛ в гептановой фракции, количество вторичных продуктов ПОЛ в изопропанольной фракции значимо выше у крыс с ЯК (см. табл. 3). Во-вторых, при сравнительной оценке продуктов ОМБ в гомогенате толстого кишечника выявлено, что при БК резервноадаптационный потенциал и суммарное содержание продуктов ОМБ выше в спонтанном и индуцированном режимах на 3-и и 7-е сутки эксперимента. Кроме того, при сравнительной оценке относительного количества первичных и вторичных продуктов ОМБ основного и нейтрального характера видно, что при БК по сравнению с ЯК на 3-и сутки превалирует содержание первичных основного характера продуктов ОМБ в спонтанном и индуцированном режимах, на 7-е сутки - содержание основного характера продуктов ОМБ в спонтанном режиме.

Полагаем, что эскалация оксидативного стресса, инициируемого продукцией АФК активированными нейтрофилами, моноцитами/макрофагами, эндотелиоцитами в очаге первичного повреждения в условиях десицита активности и/или количества ферментов антиокислительной защиты, приводит к дополнительному повреждению, дисфункции и гибели клеток толстого кишечника, расширению зоны вторичной альтерации и, как следствие, утяжелению симптомов в динамике БК и ЯК. По данным корреляционного анализа такое предположение подтверждено ассоциацией показателя клинического статуса DAI и содержания продуктов ПОЛ и продуктов ОМБ в гомогенате слизистой оболочки толстого кишечника при БК и ЯК.

\section{Литература}

1. Corridoni D, Arseneau KO, Cominelli F. Inflammatory bowel disease. Immunology Letters. 2014; 161 (2): 231-35.

2. Долгушина А. И., Хусаинова Г. М., Василенко Г. М., Кононенко А. Г. Распространенность воспалительных заболеваний кишечника в Челябинской области. Альманах клинической медицины. 2019; 47 (6): 511-17.

3. Burisch J, Munkholm P. The epidemiology of inflammatory bowel disease. Scand J Gastroenterol. 2015; 50 (8): 942-51.

4. Su HJ, Chiu YT, Chiu CT, Lin YC, Wang CY, Hsieh JY, et al. Inflammatory bowel disease and its treatment in 2018: Global and Taiwanese status updates. J Formos Med Assoc. 2019; 118 (7): 1083-92.

5. Gajendran M, Loganathan P, Catinella AP, Hashash JG A comprehensive review and update on Crohn's disease. Dis Mon. 2018 Feb; 64 (2): 20-57.

6. Ray G, Longworth MS. Epigenetics, DNA Organization, and Inflammatory Bowel Disease. Inflamm Bowel Dis. 2019; 25 (2): 235-47.

7. Lee SH, Kwon JE, Cho ML. Immunological pathogenesis of inflammatory bowel disease. Intest Res. 2018; 16 (1): 26-42.

8. Tian T, Wang Z, Zhang J. Pathomechanisms of Oxidative Stress in Inflammatory Bowel Disease and Potential Antioxidant Therapies. Oxid Med Cell Longev. 2017; 2017: 4535194

9. Zhen Y, Zhang H. NLRP3 Inflammasome and Inflammatory Bowel Disease. Front Immunol. 2019; 10 (276). URL: https://www. frontiersin.org/articles/10.3389/fimmu.2019.00276/full (дата обращения: 24.04.2020).

10. Kiernan MG, Coffey JC, Sahebally SM, Tibbitts P, Lyons EM, O'Leary E, et al. Systemic molecular mediators of inflammation differentiate between Crohn's disease and ulcerative colitis, implicating threshold levels of IL10 and relative ratios of proinflammatory cytokines in therapy. J Crohns Colitis. 2020; 14 (1):

\section{ВЫВОДЬ}

Проведенное исследование позволило выполнить поставленную цель и установить, что в динамике экспериментальных ТНБС-индуцированной БК и оксазолониндуцированного ЯК на 3-и и 7-е сутки наблюдения увеличивается индекс клинической активности болезни, в толстом кишечнике повышается количество первичных, вторичных и конечных продуктов ПОЛ в гептановой и изопропанольной фазах, повышается суммарное количество продуктов ОМБ, при БК на 7-е сутки увеличивается доля вторичных продуктов ОМБ основного характера. Особенностями СРО при ЯК выступает преимущественное накопление продуктов ПОЛ, при БК продуктов ОМБ; при ЯК прежде всего накапливаются конечные продукты ПОЛ в гептановой фазе и вторичные продукты в изопропанольной фазе липидного экстракта; при БК - вторичные продукты ОМБ основного характера. При БК и ЯК установлена ассоциация индекса клинической активности болезни и содержания продуктов ПОЛ преимущественно в изопропанольной фазе, продуктов ОМБ в спонтанном режиме; наибольшее количество сильных связей зафиксировано при ЯК. Полученные результаты расширяют имеющиеся представления о роли изменений редокс-статуса в патогенезе воспалительных заболеваний кишечника, служат предпосылкой для проведения дальнейших исследований по изучению СРО в толстом кишечнике в клинических условиях у больных БК и ЯК для обозначения продуктов ПОЛ и ОМБ в качестве диагностических маркеров заболевания, а также показателей эффективности проводимой терапии при купировании обострений и пролонгации ремиссии.
$118-119$

11. Assadsangabi A, Evans CA, Corfe BM, Lobo A. Application of Proteomics to Inflammatory Bowel Disease Research: Current Status and Future Perspectives. Gastroenterol Res Pract. 2019; 2019: 1426954

12. Titz B, Gadaleta RM, Lo Sasso G, Elamin A, Ekroos K, Ivanov NV, et al. Proteomics and Lipidomics in Inflammatory Bowel Disease Research: From Mechanistic Insights to Biomarker Identification. Int J Mol Sci. 2018; 19 (9): 2775-96.

13. Ashton JJ, Mossotto E, Ennis S. Personalising medicine in inflammatory bowel disease-current and future perspectives. Transl Pediatr. 2019; 8 (1): 56-69.

14. Morris GP, Beck PL, Herridge MS, et. al. Hapten-induced model of chronic inflammation and ulceration in the rat colon. Gastroenterology. 1989; 3: 795-803.

15. Heller F, Fuss IJ, Nieuwenhuis EE, Blumberg RS, Strober W. Oxazolone Colitis, a Th2 Colitis Model Resembling Ulcerative Colitis Is Mediated by IL13-Producing NK-T Cells. Immunity. 2002; 17 (5): 629-38.

16. Cooper HS, Murthy SN, Shah RS, et. al. Clinicopathologic study of dextran sulfate sodium ex- perimental murine colitis. Lab Invest. 1993; 69 (2): 238-49.

17. Kim JJ, Shajib MS, Manocha MM, Khan WI. Investigating intestinal inflammation in DSS-induced model of IBD. Journal of visualised experiments. 2012; 60 (60): 3678.

18. Волчегорский И. А., Долгушин И. И., Колесников О. Л., Цейликман В. Э. Экспериментальное моделирование и лабораторная оценка адаптивных реакций организма. Челябинск: ЧелГПУ, 2000; 167 с.

19. Львовская, Е. И., Волчегорский И. А., Шемяков С. Е., Лифшиц Р. И. Спектрофотометрическое определение конечных продуктов ПОЛ. Вопросы мед. химии. 1991; 4: 92-93. 
20. Дубинина Е. Е. Продукты метаболизма кислорода в функциональной активности клеток (жизнь и смерть, созидание и разрушение). Физиологические и клиникобиохимические аспекты. СПб.: Медицинская пресса, 2006; $400 \mathrm{c}$.

21. Фомина М. А. Способ комплексной оценки содержания продуктов окислительной модификации белков в тканях и биологических жидкостях: методические рекомендации. Рязань, 2014; 60 с.

22. Antoniou E, Margonis GA, Angelou A, Pikouli A, Argiri P, Karavokyros I, et al. The TNBS-induced colitis animal model: An overview. Ann Med Surg (Lond). 2016; 11: 9-15.

23. Wirtz S, Neufert C, Weigmann B, Neurath MF. Chemically induced mouse models of intestinal inflammation. Nat Protoc. 2007; 2 (3): 541-6.

24. Bramhall M, Flórez-Vargas O, Stevens R, Brass A, Cruickshank S. Quality of methods reporting in animal models of colitis. Inflamm Bowel Dis. 2015; 21 (6): 1248-59.

25. Randhawa PK, Singh K, Singh N, Jaggi AS. A review on chemicalinduced inflammatory bowel disease models in rodents. Korean $J$ Physiol Pharmacol. 2014; 18 (4): 279-88.

\section{References}

1. Corridoni D, Arseneau KO, Cominelli F. Inflammatory bowe disease. Immunology Letters. 2014; 161 (2): 231-35.

2. Dolgushina Al, Husainova GM, Vasilenko GM, Kononenko AG. Rasprostranennost' vospalitel'nyh zabolevanij kishechnika v Chelyabinskoj oblasti. Al'manah klinicheskoj mediciny. 2019; 47 (6): 511-17. Russian.

3. Burisch J, Munkholm P. The epidemiology of inflammatory bowel disease. Scand J Gastroenterol. 2015; 50 (8): 942-51.

4. Su HJ, Chiu YT, Chiu CT, Lin YC, Wang CY, Hsieh JY, et al. Inflammatory bowel disease and its treatment in 2018: Global and Taiwanese status updates. J Formos Med Assoc. 2019; 118 (7): 1083-92.

5. Gajendran $M$, Loganathan $P$, Catinella AP, Hashash JG A comprehensive review and update on Crohn's disease. Dis Mon. 2018 Feb; 64 (2): 20-57.

6. Ray G, Longworth MS. Epigenetics, DNA Organization, and Inflammatory Bowel Disease. Inflamm Bowel Dis. 2019; 25 (2): 235-47.

7. Lee SH, Kwon JE, Cho ML. Immunological pathogenesis of inflammatory bowel disease. Intest Res. 2018; 16 (1): 26-42.

8. Tian T, Wang Z, Zhang J. Pathomechanisms of Oxidative Stress in Inflammatory Bowel Disease and Potential Antioxidant Therapies. Oxid Med Cell Longev. 2017; 2017: 4535194.

9. Zhen Y, Zhang H. NLRP3 Inflammasome and Inflammatory Bowe Disease. Front Immunol. 2019; 10 (276). URL: https://www. frontiersin.org/articles/10.3389/fimmu.2019.00276/full (дата обращения: 24.04.2020).

10. Kiernan MG, Coffey JC, Sahebally SM, Tibbitts P, Lyons EM, O'Leary E, et al. Systemic molecular mediators of inflammation differentiate between Crohn's disease and ulcerative colitis, implicating threshold levels of IL10 and relative ratios of proinflammatory cytokines in therapy. J Crohns Colitis. 2020; 14 (1): 118-119.

11. Assadsangabi A, Evans CA, Corfe BM, Lobo A. Application of Proteomics to Inflammatory Bowel Disease Research: Current Status and Future Perspectives. Gastroenterol Res Pract. 2019; 2019: 1426954.

12. Titz B, Gadaleta RM, Lo Sasso G, Elamin A, Ekroos K, Ivanov NV, et al. Proteomics and Lipidomics in Inflammatory Bowel Disease Research: From Mechanistic Insights to Biomarker Identification. Int J Mol Sci. 2018; 19 (9): 2775-96.

13. Ashton JJ, Mossotto E, Ennis S. Personalising medicine in inflammatory bowel disease-current and future perspectives. Transl Pediatr. 2019; 8 (1): 56-69.

14. Morris GP, Beck PL, Herridge MS, et. al. Hapten-induced model of chronic inflammation and ulceration in the rat colon. Gastroenterology. 1989; 3: 795-803.

15. Heller F, Fuss IJ, Nieuwenhuis EE, Blumberg RS, Strober W.
26. Weigmann B, Neurath MF. Oxazolone-induced colitis as a model of Th2 immune responses in the intestinal mucosa. Methods Mol Biol. 2016; 1422: 253-61.

27. Ikeda M, Takeshima F, Isomoto H, Shikuwa S, Mizuta Y, Ozono Y, et al. Simvastatin attenuates trinitrobenzene sulfonic acid-induced colitis, but not oxazalone-induced colitis. Dig Dis Sci. 2008; 53: 1869-75.

28. Губский Ю. И., Беленичев И. Ф., Левинский Е. Л., Коваленко С. И., Павлов С. В., Ганчева О. В. и др. Токсикологические последствия окислительной модификации белков при различных патологических состояниях. Современные проблемы токсикологии. 2005; 8 (3): 20-27.

29. Dalle-Donne I, Scaloni A, Giustarini D, Cavarra E, Tell G, Lungarella G, et al. Proteins as biomarkers of oxidative stress in diseases: the contribution of redox proteomics. Mass Spectrom Rev. 2005; 24: 55-99.

30. Муравлева Л. Е., Молотов-Лучанский В. Б., Клюев Д. А., Бакенова Р. А., Култанов Б. Ж., Танкибаева Н. А. и др. Окислительная модификация белков: проблемы и перспективы исследования. Фундаментальные исследования. 2010; 1: 74-78.

Oxazolone Colitis, a Th2 Colitis Model Resembling Ulcerative Colitis Is Mediated by IL13-Producing NK-T Cells. Immunity. 2002; 17 (5): 629-38.

16. Cooper HS, Murthy SN, Shah RS, et. al. Clinicopathologic study of dextran sulfate sodium ex- perimental murine colitis. Lab Invest. 1993; 69 (2): 238-49.

17. Kim JJ, Shaijb MS, Manocha MM, Khan WI. Investigating intestinal inflammation in DSS-induced model of IBD. Journal of visualised experiments. 2012; 60 (60): 3678.

18. Volchegorskij IA, Dolgushin II, Kolesnikov OL, Cejlikman VJe. Jeksperimental'noe modelirovanie i laboratornaja ocenka adaptivnyh reakcij organizma. Cheljabinsk: ChelGPU, 2000; 167 s. Russian.

19. Lvovskaya, El, Volchegorskij IA, Shemyakov SE, Lifshic RI. Spektrofotometricheskoe opredelenie konechnyh produktov POL. Voprosy med. himii. 1991; 4: 92-93. Russian.

20. Dubinina EE. Produkty metabolizma kisloroda $\vee$ funkcional'noj aktivnosti kletok (zhizn' i smert', sozidanie i razrushenie). Fiziologicheskie i kliniko-biohimicheskie aspekty. SPb.: Medicinskaya pressa, 2006; 400 s. Russian.

21. Fomina MA. Sposob kompleksnoj ocenki soderzhaniya produktov okislitel'noj modifikacii belkov $v$ tkanyah i biologicheskih zhidkostyah: metodicheskie rekomendacii. Ryazan', 2014; 60 s. Russian.

22. Antoniou E, Margonis GA, Angelou A, Pikouli A, Argiri P, Karavokyros I, et al. The TNBS-induced colitis animal model: An overview. Ann Med Surg (Lond). 2016; 11: 9-15.

23. Wirtz S, Neufert C, Weigmann B, Neurath MF. Chemically induced mouse models of intestinal inflammation. Nat Protoc. 2007; 2 (3): $541-6$.

24. Bramhall M, Flórez-Vargas O, Stevens R, Brass A, Cruickshank S, Quality of methods reporting in animal models of colitis. Inflamm Bowel Dis. 2015; 21 (6): 1248-59.

25. Randhawa PK, Singh K, Singh N, Jaggi AS. A review on chemicalinduced inflammatory bowel disease models in rodents. Korean $\mathrm{J}$ Physiol Pharmacol. 2014; 18 (4): 279-88.

26. Weigmann B, Neurath MF. Oxazolone-induced colitis as a model of Th2 immune responses in the intestinal mucosa. Methods Mol Biol. 2016; 1422: 253-61.

27. Ikeda M, Takeshima F, Isomoto H, Shikuwa S, Mizuta Y, Ozono Y, et al. Simvastatin attenuates trinitrobenzene sulfonic acid-induced colitis, but not oxazalone-induced colitis. Dig Dis Sci. 2008; 53: 1869-75.

28. Gubskij Yul, Belenichev IF, Levinskij EL, Kovalenko SI, Pavlov SV, Gancheva OV, i dr. Toksikologicheskie posledstviya okislitel'noĭ modifikacii belkov pri razlichnyh patologicheskih sostoyaniyah. Sovremennye problemy toksikologii. 2005; 8 (3): 20-27. 


\section{ORIGINAL RESEARCH I GASTROENTEROLOGY}

29. Dalle-Donne I, Scaloni A, Giustarini D, Cavarra E, Tell G, Lungarella G, et al. Proteins as biomarkers of oxidative stress in diseases: the contribution of redox proteomics. Mass Spectrom Rev. 2005; 24: 55-99.
30. Muravleva LE, Molotov-Luchanskij VB, Klyuev DA, Bakenova RA, Kultanov BZH, Tankibaeva NA, i dr. Okislitel'naya modifikaciya belkov: problemy i perspektivy issledovaniya. Fundamental'nye issledovaniya. 2010; 1: 74-78. Russian. 